\title{
Stability and response of extremum seeking feedback scheme for squirrel cage induction generator based WECS
}

\author{
Neha Gupta*, Yaduvir Singh \\ Department of Electrical Engineering, School of Engineering, Harcourt Butlar Technical University, Kanpur (U.P.), India
}

\section{A RT ICLE INFO}

\section{Article history:}

Received 8 December 2016

Received in revised form

29 April 2017

Accepted 29 April 2017

\section{Keywords:}

Wind generator

Extremum seeking

MPPT

Stability

SCIG

\section{Introduction}

In last few decades due to environmental issues, researchers are more inclined towards the nonconventional and clean ways to produce energy. Among various non-conventional energy resources, the wind energy is considered to be most challenging source of energy because of its abundancy cleanliness, free availability and technical maturity (Chen et al., 2013; Barakati, 2008; She et al., 2013; Barote et al., 2013).

The popular structures in wind power plant include squirrel cage induction generator (SCIG) based wind power plant, doubly fed induction generator (DFIG) based wind power plant and permanent magnet synchronous generator (PMSG) based wind power plant (Wang et al., 2013; Li et al., 2012; Arani and El-Saadany, 2013). All these systems offer good efficiency, less aerodynamic loads and easy regulation of active and reactive powers. The SCIG provides flexibility under varying wind speed due to its asynchronous operation, so here in this work we have used SCIG. SCIG also offers economy, simplicity and robustness in structure against disturbance and vibration.

In order to extract maximum power from a wind power plant at variable wind speeds, an MPPT

\footnotetext{
* Corresponding Author.

Email Address: nehagupta060285@gmail.com (N. Gupta) https://doi.org/10.21833/ijaas.2017.06.007

2313-626X/C) 2017 The Authors. Published by IASE.

This is an open access article under the CC BY-NC-ND license

(http://creativecommons.org/licenses/by-nc-nd/4.0/)
}

design is required which alters the shaft speed of turbine using varying wind speed method, which intern will alter the power output, since the power output is proportional to the turbine angular velocity. This change in shaft speed is done through a power electronic interface between wind generator and grid, for which we have to control the switching of power electronic converter. Here in this paper we have used matrix (ac-dc-ac) converter instead of conventional rectifier inverter pair. The advantage of using matrix converter is that it offers bidirectional power flow capability and controllable input power factor.

In addition it has no energy storage components (Nguyen and Lee, 2013; Zhang et al., 2009). By switching of matrix converter, we alter the stator electrical frequency, which leads to the change in turbine shaft speed and drives SCIG to be maximum power point (MPP). The techniques available until now, which include perturb and observe ( $P$ \& 0 ) methods, fuzzy and neural network based techniques, are highly model dependent. The main disadvantage of model based optimization techniques is that every time we use a new model, new controller has to be designed for MPPT, which is a tedious task (Bratcu et al., 2007).

In this work we present extremum seeking scheme, which is a non-model based algorithm. Also it offers easy tenability, design simplicity and performance stoutness (She et al., 2013; Arani and El-Saadany, 2013; Komatsu et al., 2001). 


\section{Wind energy conversion system}

A general block diagram of wind energy conversion system consists of a wind turbine, a wind generator, power electronic interface to achieve MPPT at varying wind speeds and load. Here in this paper, we are using matrix converter as power electronic interface and our wind generator is squirrel cage induction generator (SCIG). Since we are modeling grid connected wind power plant, we have utility grid in place of load. In order to know the dynamics of wind turbine, we also need to model the aerodynamics of the wind turbine. The block diagram considered in this paper is shown in Fig. 1.

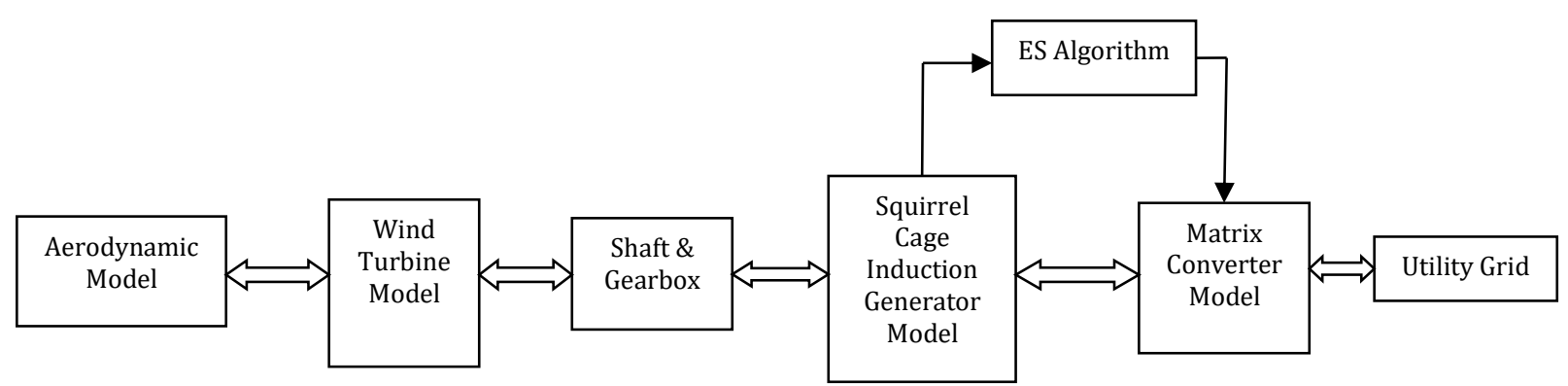

Fig. 1: Block diagram of Wind energy conversion system model under study

The power captured by the VSWT is expressed in terms of the non-dimensional power coefficient $C_{P}$, which is a measure of the ratio of the rotor power to the power available in the wind (Eq. 1):

$\mathrm{P}_{\mathrm{T}}=\frac{1}{2} \rho \mathrm{A}_{\mathrm{r}} \mathrm{C}_{\mathrm{P}}(\lambda, \beta) \mathrm{V}_{\omega}^{3}$

Maximum torque extracted from the turbine rotor can be given as (Eq. 2)

$\mathrm{T}_{\mathrm{T}}=\frac{1}{2 \omega_{\mathrm{t}}} \rho A_{\mathrm{r}} \mathrm{C}_{\mathrm{P}}(\lambda, \beta) \mathrm{V}_{\omega}^{3}$

where blade tip speed ratio is defined as

$\lambda=\frac{\text { blade tip speed }}{\text { wind speed }}=\frac{\omega_{\mathrm{t}} \times \mathrm{R}}{\mathrm{V}_{\omega}}$

$V_{\omega}=$ speed of wind in $\mathrm{m} / \mathrm{s}$

$\mathrm{A}=$ swept area of wind turbine blade

$\omega_{t}=$ turbine angular speed.

$\lambda=$ Tip speed ratio and $\beta=$ Blade pitch angle

The power coefficient $C_{p}$ is related to the tipspeed-ratio $\lambda$, and rotor blade pitch angle, $\beta$. In this study, the $C_{p}$ curve is chosen to be (Barakati, 2008) (Eq. 3):

$C_{p}=0.73 \frac{151 \frac{V_{w}}{R \omega_{t}}-13.635}{\exp \left(\frac{V_{w}}{R \omega_{t}}-0.003\right)}$

Fig. 2 shows that under the varying wind speed conditions the value of the power coefficient will be maximum, for different turbine speeds, but the maximum value of $C_{p}$ remains at the same level.

Fig. 3 shows the variation of turbine power with respect to turbine angular velocity at different wind speeds. Fig. 4 shows that if we join the points of at which the turbine power is maximum, a third-order curve is obtained, which defines the maximum power captured by the wind turbine (WT).

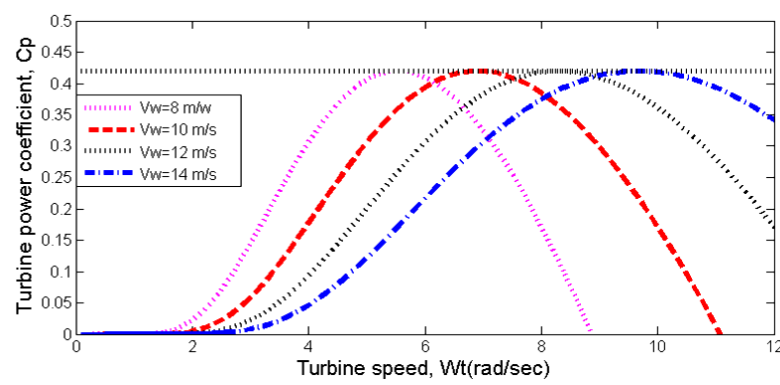

Fig. 2: power coefficient vs. turbine speed curve

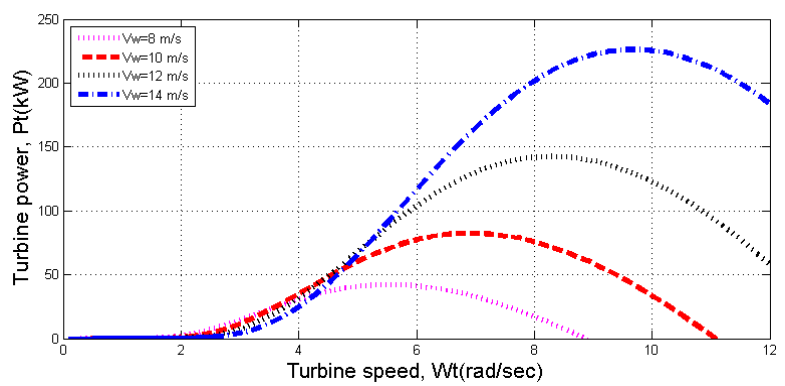

Fig. 3: Turbine power vs. turbine speed curve

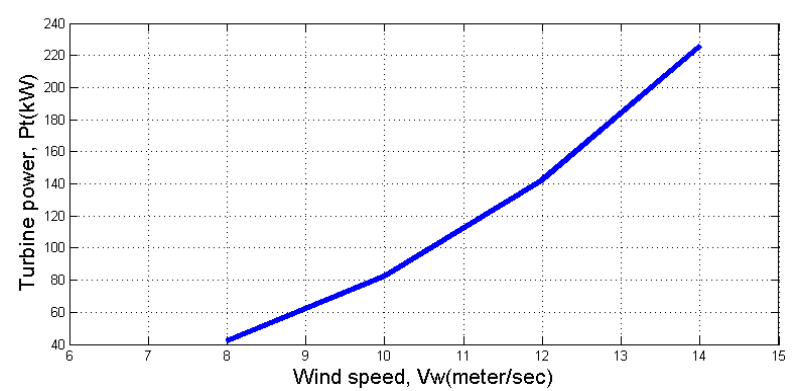

Fig. 4: Turbine speed vs. wind speed curve

The overall model for wind energy conversion system may be given by following eight nonlinear equations, which includes the state-equation of the mechanical shaft, electrical generator, and the matrix converter (Krause et al., 2013; Luca and Ulivi, 1988; Luca and Ulivi, 1989; Marino et al., 1993) (Eqs. 4-11). 


$$
\begin{aligned}
& \frac{\mathrm{d}}{\mathrm{dt}} \mathrm{i}_{\alpha}=-\mathrm{a}_{0} \mathrm{i}_{\alpha}+\mathrm{a}_{1} \lambda_{\alpha}+\mathrm{a}_{2} \omega_{\mathrm{r}} \lambda_{\beta}+\frac{\cos \theta_{0}}{\sigma \mathrm{L}_{\mathrm{s}}} \mathrm{V}_{0 \mathrm{~m}} \\
& \frac{\mathrm{d}}{\mathrm{dt}} \mathrm{i}_{\beta}=-\mathrm{a}_{0} \mathrm{i}_{\beta}+\mathrm{a}_{1} \lambda_{\beta}+\mathrm{a}_{1} \omega_{\mathrm{r}} \lambda_{\alpha}+\frac{\sin \theta_{0}}{\sigma \mathrm{L}_{\mathrm{s}}} \mathrm{V}_{0 \mathrm{~m}} \\
& \frac{\mathrm{d}}{\mathrm{dt}} \lambda_{\alpha}=\mathrm{a}_{3} \mathrm{i}_{\alpha}-\mathrm{a}_{4} \lambda_{\alpha}-\omega_{\mathrm{r}} \lambda_{\beta} \\
& \frac{\mathrm{d}}{\mathrm{dt}} \lambda_{\beta}=\mathrm{a}_{3} \mathrm{i}_{\beta}-\mathrm{a}_{4} \lambda_{\beta}+\omega_{\mathrm{r}} \lambda_{\alpha} \\
& \frac{\mathrm{d}}{\mathrm{dt}} \theta_{0}=\omega_{0} \\
& \frac{\mathrm{d}}{\mathrm{dt}} \omega_{\mathrm{r}}=\frac{3 \mathrm{p}^{2} \mathrm{~L}_{\mathrm{m}}}{2 \mathrm{~L}_{\mathrm{r}} \mathrm{J}}\left(\mathrm{i}_{\beta} \lambda_{\alpha}-\mathrm{i}_{\alpha} \lambda_{\beta}\right)-\frac{\mathrm{pK}}{\mathrm{nJ}} \tilde{\theta}-\frac{\mathrm{pB}}{\mathrm{nJ}}\left(\omega_{\mathrm{t}}-\frac{\omega_{\mathrm{r}}}{\mathrm{pn}}\right) \\
& \frac{\mathrm{d}}{\mathrm{dt}} \tilde{\theta}=\omega_{\mathrm{t}}-\frac{\omega_{\mathrm{r}}}{\mathrm{pn}} \\
& \frac{\mathrm{d}}{\mathrm{dt}} \omega_{\mathrm{t}}=-\frac{\mathrm{P}_{\mathrm{t}}\left(\mathrm{V}_{\mathrm{w}}, \omega_{\mathrm{t}}\right)}{\mathrm{J}_{\mathrm{t}} \omega_{\mathrm{t}}}-\frac{\mathrm{K}_{\mathrm{s}}}{\mathrm{J}_{\mathrm{t}}} \tilde{\theta}-\frac{\mathrm{B}}{\mathrm{J}_{\mathrm{t}}}\left(\omega_{\mathrm{t}}-\frac{\omega_{\mathrm{r}}}{\mathrm{pn}}\right)
\end{aligned}
$$

\section{Extremum seeking for maximum power point tracking in wind energy conversion system}

A typical power curve of a WECS as shown in Fig. 5 can be divided into four major regions. The first region contains the velocities below which turbine is not able to generate any power due to insufficient wind. The second region contains the wind velocities from where the generation starts to the velocity up till which the power linearly increases with increase in wind velocity. This region is known as sub-rated power region. This is the region where MPPT schemes are applied to extract maximum power. The third region consists of wind velocities which are sufficient for wind turbine to reach rated power, hence power output is limited by wind turbine. The fourth region contains the velocities of wind which are much stronger and may cause damage to wind turbine, hence in this region, the turbine is shut down (Ghaffari et al., 2014).

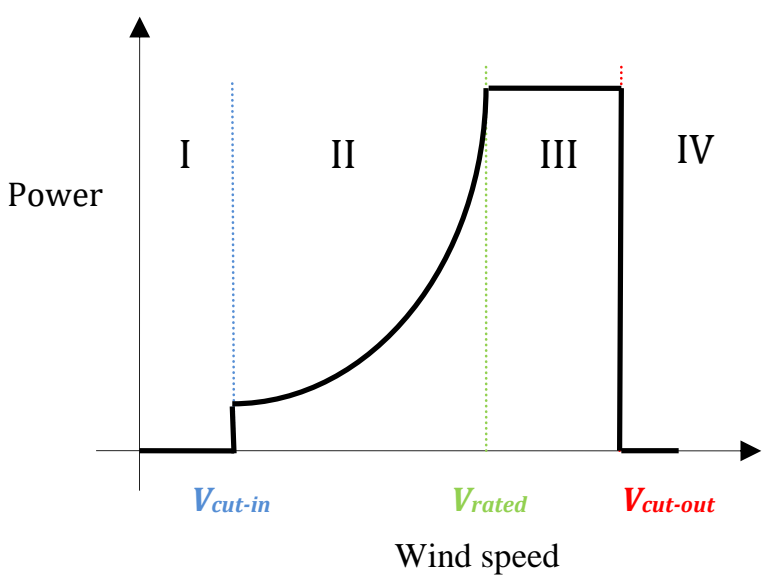

Fig. 5: Typical power curve of WT including four operating regions (Ghaffari et al., 2014)

Now in this section we present the extremum seeking technique for WECS, which is a real time optimization techniques and unlike conventional MPPT algorithms it does not require system modeling and identification as it is a non-model based optimization technique. For simulation purpose the models of power coefficient and turbine power are given Eqs. 3 and 4.

Here we assume that we can measure and manipulate turbine power through MC. Also, we know that the turbine power map has one MPP under any wind speed. On the basis of which we present the following assumption. This assumption is for the turbine power map around its MPP for $V_{\text {cut in }}<V_{w}<V_{\text {rated }}$ (Fig. 5) (Eqs. 12 and 13).

$\frac{\partial \mathrm{P}_{\mathrm{t}}\left(\mathrm{V}_{\mathrm{w}}, \omega_{\mathrm{t}}\right)}{\partial \omega_{\mathrm{t}}}\left(\omega_{\mathrm{t}}^{*}\right)=0$

$\frac{\partial^{2} \mathrm{P}_{\mathrm{t}}\left(\mathrm{V}_{\mathrm{w}}, \omega_{\mathrm{t}}\right)}{\partial^{2} \omega_{\mathrm{t}}}\left(\omega_{\mathrm{t}}^{*}\right)<0$

If, we carefully study the torque speed characteristics of an induction machine, it is observed that this curve is very sharp near the synchronous speed (stator electrical frequency), $\omega_{0}$. At this point the rotor electrical speed $\omega_{r}$ and synchronous speed $\omega_{0}$ will be nearly equal. This indicates that if we change the stator electrical frequency, the electrical rotor speed will change, which intern will change the turbine speed $\omega_{t}$ (Ghaffari et al., 2014). Thus by varying $\omega_{0}$ through $\mathrm{MC}$, we may change turbine speed $\omega_{t}$ to track MPPT. Our ES scheme works on the same line.

Fig. 6 shows the schematic of this work in which, we have employed extremum seeking feedback in WECS for MPPT. In order to track maximum power we change stator electrical frequency $\omega_{0}$. The amount and direction of change is estimated by the ES feedback loop (Komatsu et al., 2001; Kumar et al., 2009; Pan et al., 2008; Ghaffari et al., 2014) (Eqs. 1416).

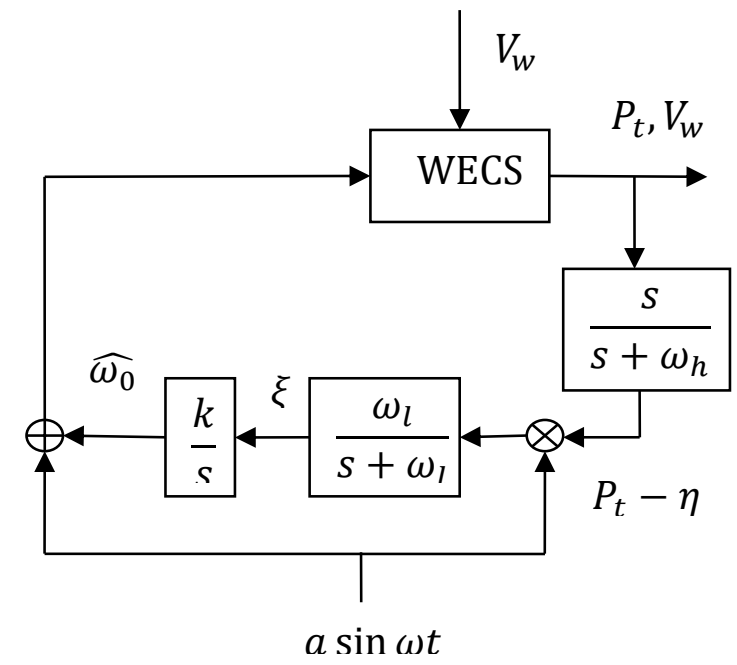

Fig. 6: Extremum seeking for MPPT in WECS

$\omega_{\mathrm{h}}=\omega \omega_{\mathrm{H}}=\omega \delta \omega_{\mathrm{H}}^{\prime}=0(\omega \delta)$
$\omega_{\mathrm{l}}=\omega \omega_{\mathrm{L}}=\omega \delta \omega_{\mathrm{L}}^{\prime}=0(\omega \delta)$
$\mathrm{k}=\omega \mathrm{K}=\omega \delta \mathrm{K}^{\prime}=\mathrm{O}(\omega \delta)$

where $\omega, \delta=$ small positive constants and $\omega_{H}^{\prime}, \omega_{L}^{\prime}$ and $K^{\prime}=\mathrm{O}(1)$ positive constants.

By inspecting Eqs. 14 and 15 we can see that while designing low pass filter and high pass filter for extremum seeking feedback it should note that cut off frequencies of both the filter must be lesser than that of the perturbation signal. Furthermore, for convergence of ES scheme it is necessary that the value of adaptation gain $\mathrm{k}$ must be very small. 
4. Stability analysis of extremum seeking feedback for IG based wind power plant

In order to track maximum power through extremum seeking feedback scheme, the desired closed loop performance of wind power plant is obtained by varying voltage amplitude of stator and electrical frequency of stator through matrix converter. To obtain input output decoupling in the dynamics of wind power plant, we employ field oriented control (FOC), an auxiliary input and an integrator (Luca and Ulivi, 1988; Luca and Ulivi, 1989; Marino et al., 1993). By making use of equations (4)-(13) and one step of integration in front of $V_{0 m}$, the modified equations of WECS are given as follows (Eq. 17):

$\dot{\mathrm{x}}=\mathrm{f}(\mathrm{x})+\mathrm{g}_{1} \mathrm{u}_{1}+\mathrm{g}_{2} \mathrm{u}_{2}$

where $u_{1}=$ stator electrical frequency, $\omega_{0} u_{2}=$ rate of voltage amplitude. It is used to generate the voltage amplitude of the SCIG stator.

The extremum seeking feedback loop gives the estimates $\omega_{0}$ for MPPT. The other input $u_{2}$ has been set to zero i.e. Stator voltage has constant peak amplitude. Hence (Eqs. 18-29),

$$
\begin{aligned}
& \dot{x}=f(x)+g_{1} u_{1}, x \in R^{9}, u \in R \\
& y=\omega_{t}, y \in R \\
& f(x)=\left[\begin{array}{c}
-a_{0} x_{1}+a_{1} x_{3}+a_{2} x_{4} x_{7}+\frac{x_{6} \cos x_{5}}{\sigma L_{s}} \\
-a_{0} x_{2}+a_{1} x_{4}+a_{2} x_{3} x_{7}+\frac{x_{6} \cos x_{5}}{\sigma L_{s}} \\
a_{3} x_{1}-a_{4} x_{3}-x_{4} x_{7} \\
a_{3} x_{2}-a_{4} x_{4}+x_{3} x_{7} \\
0 \\
0 \\
a_{5}\left(x_{2} x_{3}-x_{1} x_{4}\right)-a_{6} x_{8}-a_{5}\left(x_{9}-\frac{x_{7}}{p n}\right) \\
x_{9}-\frac{x_{7}}{p n} \\
-a_{9}\left(x_{9}-\frac{x_{7}}{p n}\right)-a_{8} x_{8}-\frac{T_{t}}{J_{t}}
\end{array}\right]
\end{aligned}
$$

suppose that we know the control law

$\mathrm{u}=\alpha\left(\mathrm{x}, \omega_{0}\right)$

parameterized by $\omega_{0}$. The closed loop system

$\dot{x}=f\left(x, \alpha\left(x, \omega_{0}\right)\right)$

then has equlibria parameterized by $\omega_{0}$. the system of Fig. 6 may be summarized as-

$\dot{\mathrm{x}}=\mathrm{f}\left(\mathrm{x}, \alpha\left(\mathrm{x}, \widehat{\omega_{0}}+\mathrm{a} \sin \omega \mathrm{t}\right)\right)$,

$\widehat{\omega_{0}} \dot{=} \mathrm{k} \xi$,

$\dot{\xi}=-\omega_{l} \xi+\omega_{l}(y-\eta) a \sin \omega t$,

$\dot{\eta}=-\omega_{\mathrm{h}} \eta+\omega_{\mathrm{h}} \mathrm{y}$

After applying the following coordinate transform

$\widetilde{\omega_{0}}=\widehat{\omega_{0}}-\omega_{0}^{*}$

$\tilde{\eta}=\eta-\mathrm{h} \circ \mathrm{l}\left(\omega_{0}^{*}\right)$,
The system (23)-(25) can be rewritten in $\tau=\omega t$ as (Eqs. 28-29)

$\omega \frac{d x}{d \tau}=f\left(x, \alpha\left(x, \widehat{\omega_{0}}+a \sin \tau\right)\right)$

$\frac{\mathrm{d}}{\mathrm{d} \tau}\left[\begin{array}{c}\widetilde{\omega_{0}} \\ \xi \\ \tilde{\eta}\end{array}\right]=\delta\left[\begin{array}{c}\mathrm{K}^{\prime} \xi \\ -\omega_{\mathrm{L}}^{\prime} \xi+\omega_{\mathrm{L}}^{\prime}\left(\mathrm{h}(\mathrm{x})-\mathrm{h} \circ \mathrm{l}\left(\omega_{0}^{*}\right)-\tilde{\eta}\right) \mathrm{a} \sin \tau \\ -\omega_{\mathrm{H}}^{\prime} \tilde{\eta}+\omega_{\mathrm{H}}^{\prime}\left(\mathrm{h}(\mathrm{x})-\mathrm{h} \circ \mathrm{l}\left(\omega_{0}^{*}\right)\right)\end{array}\right]$

Before proceeding for the proof of stability we make following assumptions:

Assumption 1: Here, we assume that there exists a smooth functional in such a way that $\mathrm{f}\left(\mathrm{x}, \alpha\left(\mathrm{x}, \omega_{0}\right)\right)=$ 0 iff $=l\left(\omega_{0}\right)$ (Krstić and Wang, 2000).

Assumption 2: With overshoot and decay constants uniform in $\omega_{0}$, the system is locally exponentially stable for each $\omega_{0} \epsilon R$, the equilibrium $x=l\left(\omega_{0}\right)$ (Krstić and Wang, 2000).

In view of above two assumptions, we consider that the control law depicted in Eq. 20 is stout for its parameter $\omega_{0}$, this signifies that it is able to exponentially stabilize any equilibria produced by $\omega_{0}$ with an exception that the requirements as given by assumption 2 satisfy, $\forall \omega_{0} \in R$. This assumption is not limited to existing model but once we have designed the local stabilization of control law, the same may be applicable without the modeling knowledge of either $f(x, u)$ or $l\left(\omega_{0}\right)$.

One more, very essential assumption for this scheme is assumption 3

Assumption 3: Here we assume that $\ni \omega_{0}^{*} \in \mathrm{R}$ :

$(\mathrm{h} \circ \mathrm{l})^{\prime}\left(\omega_{0}^{*}\right)=0$

$(\mathrm{h} \circ \mathrm{l})^{\prime \prime}\left(\omega_{0}^{*}\right)<0$

The combination of above two equations signify the condition for maxima i.e. the output equilibrium map $y=h\left(l\left(\omega_{0}\right)\right)$ will have its maxima at $\omega_{0}=\omega_{0}^{*}$. The main objective is to develop the ES feedback mechanism in such a way that maximization of steady state value of $y$ does not require any knowledge of either $\omega_{0}^{*}$ or the functions $h$ and $l$. If we replace y by $-y$ in ES feedback design, we will be able to track minima of output equilibrium map without loss of generality

\section{Stability analysis using singular perturbation method}

To make the notations further simpler we write (29) as (Eq. 30)

$\frac{\mathrm{dz}}{\mathrm{d} \tau}=\delta \mathrm{G}(\tau, \mathrm{x}, \mathrm{z})$

where $z=\left(\widetilde{\omega_{0}}, \xi, \tilde{\eta}\right)$. By (Theorem 4.1 in (Krstić and Wang, 2000)) there exists an exponentially stable periodic solution $z_{r}^{2 \pi}(\tau)$ such that (Eq. 31)

$\frac{\mathrm{dz}_{\mathrm{r}}^{2 \pi}(\tau)}{\mathrm{d} \tau}=\delta \mathrm{G}\left(\tau, \mathrm{L}\left(\mathrm{z}_{\mathrm{r}}^{2 \pi}(\tau)\right), \mathrm{z}_{\mathrm{r}}^{2 \pi}(\tau)\right)$ 
where $L(\tau, z)=l\left(\omega_{0}^{*}+\widehat{\omega_{0}}+a \sin \tau\right)$. To bring the system (30) and (31) in the standard perturbation form, we shift state $\mathrm{z}$ using the transformation (Eqs. 32-36)

$\tilde{\mathrm{z}}=\mathrm{z}-\mathrm{z}_{\mathrm{r}}^{2 \pi}(\tau)$

and get

$\frac{\mathrm{d} \tilde{\mathrm{z}}}{\mathrm{d} \tau}=\delta \mathrm{G}(\tau, \mathrm{x}, \tilde{\mathrm{z}})$

$\omega \frac{d x}{d \tau}=\tilde{F}(\tau, x, \tilde{z})$

where

$\widetilde{G}(\tau, x, \tilde{z})=\widetilde{G}\left(\tau, x, \tilde{z}+z_{r}^{2 \pi}(\tau)\right)-G\left(\tau, L\left(z_{r}^{2 \pi}(\tau)\right), z_{r}^{2 \pi}(\tau)\right.$

$\tilde{\mathrm{F}}(\tau, x, \tilde{z})=f\left(x, \alpha\left(x, \omega_{0}^{*}+\widetilde{\omega_{0}}-\widetilde{\omega}_{0 r}^{2 \pi}(\tau)+\widetilde{\omega}_{0 r}^{2 \pi}(\tau)+a \sin \tau\right.\right.$,

we note that (Eq. 37)

$\mathrm{x}=\mathrm{L}\left(\tau, \tilde{z}+\mathrm{zr}_{\mathrm{r}}^{2 \pi}(\tau)\right)$

is the quasi-steady state, and that the reduced model (Eq. 38)

$\frac{d \widetilde{\tau_{r}}}{d \tau}=\delta G\left(\tau, L\left(\tau, \widetilde{z_{r}}+z_{r}^{2 \pi}(\tau)\right), \widetilde{z_{r}}+z_{r}^{2 \pi}(\tau)\right)$

has an equilibrium at the origin $\widetilde{z_{r}}=0$ (cf. (35) with (37)). The exponential stability of his equilibrium can be ensured if the value of $a$,is sufficiently small (Krstić and Wang, 2000). Singular perturbation analysis is incomplete without the study of boundary layer model. In the time scale $t-t_{0}=\frac{\tau}{\omega}$ (Eq. 39)

$\frac{\mathrm{dx}_{\mathrm{b}}}{\mathrm{dt}}=\tilde{\mathrm{F}}\left(\tau, \mathrm{x}_{\mathrm{b}},+\mathrm{L}\left(\tau, \widetilde{\mathrm{z}_{\mathrm{r}}}+\mathrm{z}_{\mathrm{r}}^{2 \pi}(\tau)\right), \tilde{\mathrm{z}}\right)=\mathrm{f}\left(\mathrm{x}_{\mathrm{b}}+\right.$

$\left.\mathrm{l}\left(\omega_{0}\right), \alpha\left(\mathrm{x}_{\mathrm{b}}+\mathrm{l}\left(\omega_{0}\right)\right), \omega_{0}\right)$

Here it is worth noting that the expression $\omega_{0}=$ $\omega_{0}^{*}+\widetilde{\omega_{0}}+a \sin \tau$, is not depending on the time variable $t$. Since $f\left(l\left(\omega_{0}\right), \alpha\left(x_{b}+l\left(\omega_{0}\right)\right), \omega_{0}\right) \equiv 0$, this signifies that eq (39) hs its equilibrium at $x_{b}=0$. According to the assumption 2 equilibrium is stable exponentially and uniformly in in $\omega_{0}$ and hence $\left.l\left(\omega_{0}\right)\right)$.

By combining exponential stability of the reduced model (38) with the exponential stability of the boundary layer model (39), using Tikhonov's Theorem on the Infinite Interval [Theorem 9.4 in (Khalil, 1996), we deduce that:

The $z(\tau)$ converges exponentially to an $O(\omega)$ surrounding of the periodic solution $z_{r}^{2 \pi}(\tau)$, as the solution $(\tau)$ of eq (30) is $O(\omega)$ close to the solution $z_{r}(\tau)$ of Eq. 38. Further $z_{r}(\tau)$ is in $O(\omega)$ neighborhood of the equilibrium $z_{r}^{a, e}$, which indicates that the solution of $\widetilde{\omega_{0}}(\tau)$ of (29) converges exponentially to an $O(\omega+\delta)$ - surrounding of $\left.\left\{[h \circ l]^{\prime \prime \prime}\left(\omega_{0}^{*}\right) /\left[8\left(h \circ l^{\prime \prime}\left(\omega_{0}^{*}\right)\right]\right\} a^{2}+O\left(a^{3}\right)\right]\right\} \quad$ i.e. $\omega_{0}(\tau)=\omega_{0}^{*}+\widetilde{\omega_{0}}(\tau)+a \sin \tau \quad$ converges exponentially to an $O(\omega+\delta+a)$ - surrounding of $\omega_{0}^{*}$. The solution $x(\tau)$ of (34) satisfies (Eq. 40) $x(\tau)-l\left(\omega_{0}^{*}+\widetilde{\omega_{0}}(\tau)+a \sin \tau\right)-x_{b}(t)=O(\omega)$

where, $\omega_{0 r}(\tau)$ is the solution of the reduced model (20) and $x_{b}(t)$ is the solution of the boundary layer model (39). From (40) we get (Eq. 41)

$x(\tau)-l\left(\omega_{0}^{*}\right)=l\left(\omega_{0}^{*}+\widetilde{\omega_{0}}(\tau)+a \sin \tau\right)-x_{b}(t)+O(\omega)-$

$l\left(\omega_{0}^{*}\right)$

The exponential convergence of $\omega_{0 r}(\tau)$ to the periodic solution $\widetilde{\omega}_{0 r}^{2 \pi}(\tau), O(\delta)$ close to the average equilibrium $\quad\left\{[h \circ l]^{\prime \prime \prime}\left(\omega_{0}^{*}\right) /\left[8\left(h \circ l^{\prime \prime}\left(\omega_{0}^{*}\right)\right]\right\} a^{2}+\right.$ $O\left(a^{3}\right)$, together with the exponentially decaying solution $x_{b}(t)$ of (39) and exponential convergence of $x(\tau)-l\left(\omega_{0}^{*}\right)$ by Eq. 41 an $O(\omega+\delta+a)$ neighborhood of zero ensures the exponential convergence of $y=h(x)$ to an $O(\omega+\delta+a)$ surrounding of its maximal equilibrium $h \circ l\left(\omega_{0}^{*}\right)$.

\section{Simulation results}

The proposed extremum seeking feedback scheme for MPPT in WECS has been evaluated by testing it for different disturbances i.e. variation of wind speeds in subrated power region using MATLAB m-file. Simulation results are presented below. Fig. 7 shows the variation of wind speed with time, which is applied to WECS. Fig. 8 shows the responses of the proposed WECS incorporating the ES based control of SCIG for changes in wind speed as shown in Fig. 7. It is seen from Fig. 9 that despite rapid change in wind speed power coefficient turbine torque follows smoothly according to the disturbances in wind speed $C_{P}$ is regulated to almost a constant value with slight variation of the order of $10^{-4}$, while the power level increases as wind speed increases.

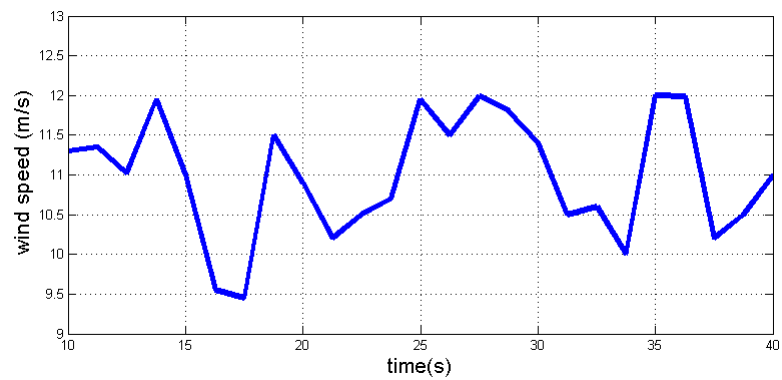

Fig. 7: Variation of wind speed versus time

\section{Conclusion}

In this paper, we have presented extremum seeking feedback algorithm for maximum power point tracking in WECS. ES scheme estimates the stator electrical frequency to steer the wind turbine to its maximum power point. We have checked the performance of this control system for rapid wind variations and found that as soon as we change the wind velocity the ES scheme steers the wind turbine to its corresponding MPP. The advantageous feature of this work is that it does not require knowledge of wind speed, turbine or generator parameters. So, 
once we have designed the controller, it can be applied to any WECS model. We have also done the stability analysis of Es scheme for WECS and found that it successfully converges at MPP.

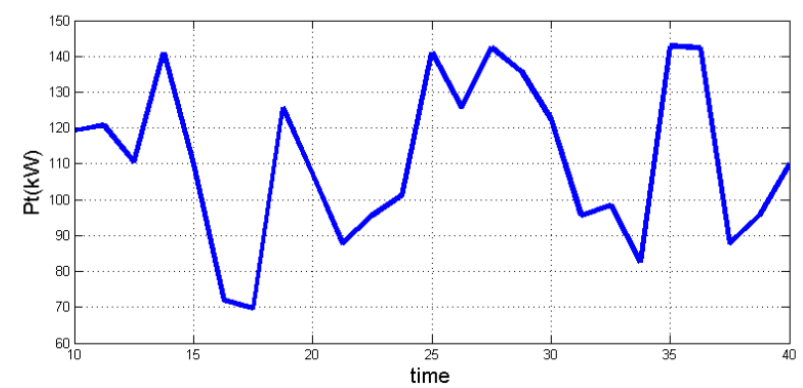

Fig. 8: MPPT process using ES scheme

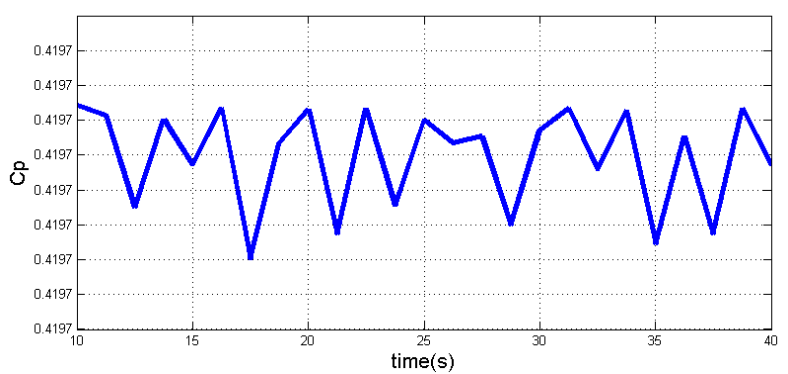

Fig. 9: Variation of power coefficient

\section{Constant parameters}

$\begin{array}{cc}a_{0} & a_{2} a_{3}+\frac{R_{s}}{\sigma L_{s}}, \\ a_{1} & a_{2} a_{4} \\ a_{2} & \frac{L_{m}}{\sigma L_{s} L_{r}} \\ & \frac{L_{m} R_{r}}{L_{r}} \\ a_{3} & \frac{R_{r}}{L_{r}} \\ a_{4} & 3 p^{2} L_{m} / 2 J L_{r} \\ a_{5} & p K_{s} / J n \\ a_{6} & p B / J n \\ a_{7} & K_{s} / J_{t} \\ a_{8} & B / J_{t} \\ a_{9} & \end{array}$

\section{References}

Arani MFM and El-Saadany EF (2013). Implementing virtual inertia in DFIG-based wind power generation. IEEE Transactions on Power Systems, 28(2): 1373-1384.

Barakati SM (2008). Modeling and controller design of a wind energy conversion system including a matrix converter. Ph.D. Dissertation, University of Waterloo, Ontario, Canada.

Barote L, Marinescu C, and Cirstea MN (2013). Control structure for single-phase stand-alone wind-based energy sources. IEEE Transactions on Industrial Electronics, 60(2): 764-772.

Bratcu AI, Munteanu I, Ceanga E, and Epure S (2007). Energetic optimization of variable speed wind energy conversion systems by extremum seeking control. In the International Conference on "Computer as a Tool" EUROCON, IEEE: 25362541. https://doi.org/10.1109/EURCON.2007.4400523
Chen J, Chen J, and Gong C (2013). On optimizing the transient load of variable speed wind energy conversion system during MPP tracking process. IEEE Transaction on Industrial Electronics, 61(9): 4698-4706.

Ghaffari A, Krstic M, and Seshagiri S (2014). Power optimization and control in wind energy conversion systems using extremum seeking. IEEE Transactions on Control Systems Technology, 22(5): 1684-1695.

Khalil HK (1996). Noninear systems. Prentice-Hall, New Jersey, USA.

Komatsu M, Miyamoto H, Ohmori H, and Sano A (2001). Output maximization control of wind turbine based on extremum control strategy. In the Conference of the American Control, 2: 1739-1740. https://doi.org/10.1109/ACC.2001.945982

Krause PC, Wasynczuk O, Sudhoff SD, and Pekarek S (2013). Analysis of electric machinery and drive systems. John Wiley and Sons, New York, USA.

Krstić M and Wang HH (2000). Stability of extremum seeking feedback for general nonlinear dynamic systems. Automatica, 36(4): 595-601.

Kumar V, Joshi RR, and Bansal RC (2009). Optimal control of matrix-converter-based WECS for performance enhancement and efficiency optimization. IEEE Transactions on Energy Conversion, 24(1): 264-273.

Li S, Haskew TA, Williams KA, and Swatloski RP (2012). Control of DFIG wind turbine with direct-current vector control configuration. IEEE Transactions on Sustainable Energy, 3(1): $1-11$.

Luca AD and Ulivi G (1988). Dynamic decoupling of voltage frequency controlled induction motors. In the $8^{\text {th }}$ International Conference on Analysis and Optimization of Systems, 111: 127-137. https://doi.org/10.1007/bfb0042208

Luca AD and Ulivi G (1989). Design of an exact nonlinear controller for induction motors. IEEE Transactions on Automatic Control, 34(12): 1304-1307.

Marino R, Peresada S, and Valigi P (1993). Adaptive input-output linearizing control of induction motors. IEEE Transactions on Automatic control, 38(2): 208-221.

Nguyen TH and Lee DC (2013). Advanced fault ride-through technique for PMSG wind turbine systems using line-side converter as STATCOM. IEEE Transactions on Industrial Electronics, 60(7): 2842-2850.

Pan T, Ji Z, and Jiang Z (2008). Maximum power point tracking of wind energy conversion systems based on sliding mode extremum seeking control. In the IEEE Energy 2030 Conference, IEEE: 1-5. https://doi.org/10.1109/ENERGY. 2008.4781032

She X, Huang AQ, Wang F, and Burgos R (2013). Wind energy system with integrated functions of active power transfer, reactive power compensation, and voltage conversion. IEEE Transactions on Industrial Electronics, 60(10): 4512-4524.

Wang N, Johnson KE, and Wright AD (2013). Comparison of strategies for enhancing energy capture and reducing loads using LIDAR and feed forward control. IEEE Transactions on Control Systems Technology, 21(4): 1129-1142.

Zhang S, Tseng KJ, and Nguyen TD (2009). May. Modeling of AC-AC matrix converter for wind energy conversion system. In the $4^{\text {th }}$ IEEE Conference on Industrial Electronics and Applications (ICIEA 2009). IEEE: 184-191. https://doi.org/10.1109/ICIEA. 2009.5138193 